\title{
Palinologia de sedimentos da turfeira do Banhado Amarelo, São Francisco de Paula, Rio Grande do Sul, Brasil. Gimnospermas e angiospermas
}

\author{
Bianca Batista da Costa Spalding ${ }^{1,2}$ e Maria Luisa Lorscheitter ${ }^{1}$
}

Recebido: 23.12.2009; aceito: 17.06.2010

\begin{abstract}
Peat palynology from the "Banhado Amarelo" bog, São Francisco de Paula, Rio Grande do Sul, Brazil. Gymnospermae and Angiospermae). Taxonomic studies of pollen in sediments are reference for paleoenvironmental reconstruction studies. The aim of this research is to present pollen material preserved in the peat from "Banhado Amarelo" bog (29 $19^{\circ} \mathrm{S}$ and $\left.50^{\circ} 08^{\prime} \mathrm{W}\right)$, São Francisco de Paula, RS to paleoenvironment analysis of Quaternary from the Brazilian Southern Plateau. The profile $(390 \mathrm{~cm})$ was collected with a Hiller Sampler. The chemical processing of the 30 extracted samples followed standard methodology, using $\mathrm{HCl}, \mathrm{HF}, \mathrm{KOH}$ and acetolysis. Light microscopy was used in the analysis. A radiocarbon dating near the base of the profile $(26.080 \pm 320 \mathrm{yrs}$ BP, Beta 245611) indicated the time interval. Palynomorphs belonging to two gymnospermous and 44 angiospermous taxa are presented. Descriptions, illustrations and ecological data from the original organisms are included. The high number of taxa show the potential of this material to offers subsidies to the vegetation dynamic and climate studies from Southern Brazilian Plateau of the last millennia.
\end{abstract}

Keywords: palynology, Quaternary, Southern Brazil, taxonomy

RESUMO - (Palinologia de sedimentos da turfeira do Banhado Amarelo, São Francisco de Paula, Rio Grande do Sul, Brasil. Gimnospermas e angiospermas). Estudos taxonômicos de pólen contido em sedimentos servem de referência para estudos de reconstituição paleoambiental. O trabalho visa, assim, fornecer subsídios para a análise de paleoambientes do Quaternário do Planalto sul-brasileiro, através da análise taxonômica do material polínico preservado num perfil sedimentar

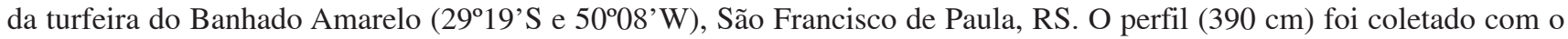
Amostrador de Hiller e dele extraídas 30 amostras, tratadas pelo método padrão, com $\mathrm{HCl}, \mathrm{HF}, \mathrm{KOH}$ e acetólise, e analisa-

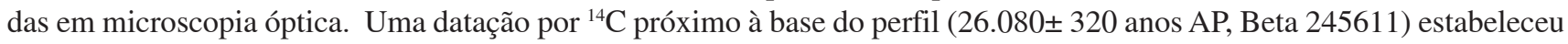
o intervalo de tempo envolvido. Foram encontrados dois táxons de gimnospermas e 44 de angiospermas. Incluem-se descrições, ilustrações e dados ecológicos da planta de origem. A riqueza de táxons mostra a potencialidade do material polínico em fornecer subsídios ao estudo da dinâmica da vegetação e clima do Planalto sul-brasileiro nos últimos milênios Palavras-chave: palinologia, Quaternário, Sul do Brasil, taxonomia

\section{Introdução}

Os padrões fitogeográficos da atualidade são também resultantes das mudanças climáticas e vegetacionais ocorridas no passado. Essas mudanças podem ser detectadas em estudos de sucessão vegetal, que permitem o conhecimento dos processos históricos envolvidos na gênese das formações vegetais e a compreensão da dinâmica e das tendências naturais da vegetação e do clima, importantes na avaliação e monitoramento ambiental.
Grãos de pólen e esporos possuem características morfológicas típicas para cada táxon, o que permite inferir o habitat correspondente. Portanto, ao caírem em ambientes deposicionais apropriados que permitam sua preservação, oferecem farto material para estudos de sucessão vegetal e análises paleoambientais. A correta identificação taxonômica dos palinomorfos é imprescindível para esses estudos por embasar toda a investigação, necessitando de catálogos de referência tanto de pólen e esporos atuais como de material extraído de sedimentos.

1. Universidade Federal do Rio Grande do Sul, Instituto de Biociências, Departamento de Botânica, Av. Bento Gonçalves 9500 , 91540-000 Porto Alegre, RS, Brasil

2. Autor para correspondência: biancaspalding@gmail.com 
Trabalhos taxonômicos de palinologia de sedimentos, com o objetivo de fornecer material de referência para estudos paleoambientais no Planalto do Rio Grande do Sul, são ainda muito poucos, e foram realizados por Roth (1990), Leonhardt (2007), Leonhardt \& Lorscheitter (2007, 2008), Roth \& Lorscheitter (2008), Scherer (2008), Scherer \& Lorscheitter (2008, 2009) e Spalding \& Lorscheitter (2009).

O presente trabalho apresenta os resultados da segunda parte da análise palinológica desenvolvida num perfil sedimentar na turfeira do Banhado Amarelo, município de São Francisco de Paula, Planalto oriental do Rio Grande do Sul, abrangendo a taxonomia do pólen de gimnospermas e angiospermas como material de referência.

\section{Material e métodos}

A turfeira estudada compõe o Banhado Amarelo (29¹9'S e 5008'W), município de São Francisco de Paula, Planalto oriental do Rio Grande do Sul (figu- ra 1). O perfil sedimentar foi coletado aproximadamente no centro da turfeira, correspondendo à porção mais espessa da bacia deposicional. Para a determinação do intervalo de tempo envolvido utilizou-se uma datação por ${ }^{14} \mathrm{C}$ em sedimentos próximos à base da seqüência, realizada no laboratório Beta Analytic Inc., Miami, Flórida.

A coleta do perfil foi realizada com Amostrador de Hiller (Faegri \& Iversen 1989), em 15 secções de $26 \mathrm{~cm}$, que foram posteriormente alinhadas, formando um testemunho de $390 \mathrm{~cm}^{3}$ de comprimento. Ao longo desse perfil foram extraídas 30 amostras a intervalos regulares, cada uma com $8 \mathrm{~cm}^{3}$ de sedimento fresco. O processamento químico das amostras seguiu o método padrão (Faegri \& Iversen 1989), usando-se $\mathrm{HCl}, \mathrm{HF}, \mathrm{KOH}$ e acetólise, com filtragem em malha de $250 \mu \mathrm{m}$. O material polínico foi montado em lâminas com gelatina-glicerinada e a análise realizada em fotomicroscópio óptico Diaplan Leitz, em aumento de 400 vezes. O pólen de cada táxon foi fotomicrografado em aumento de 1.000 vezes (filme T-MAX 100).
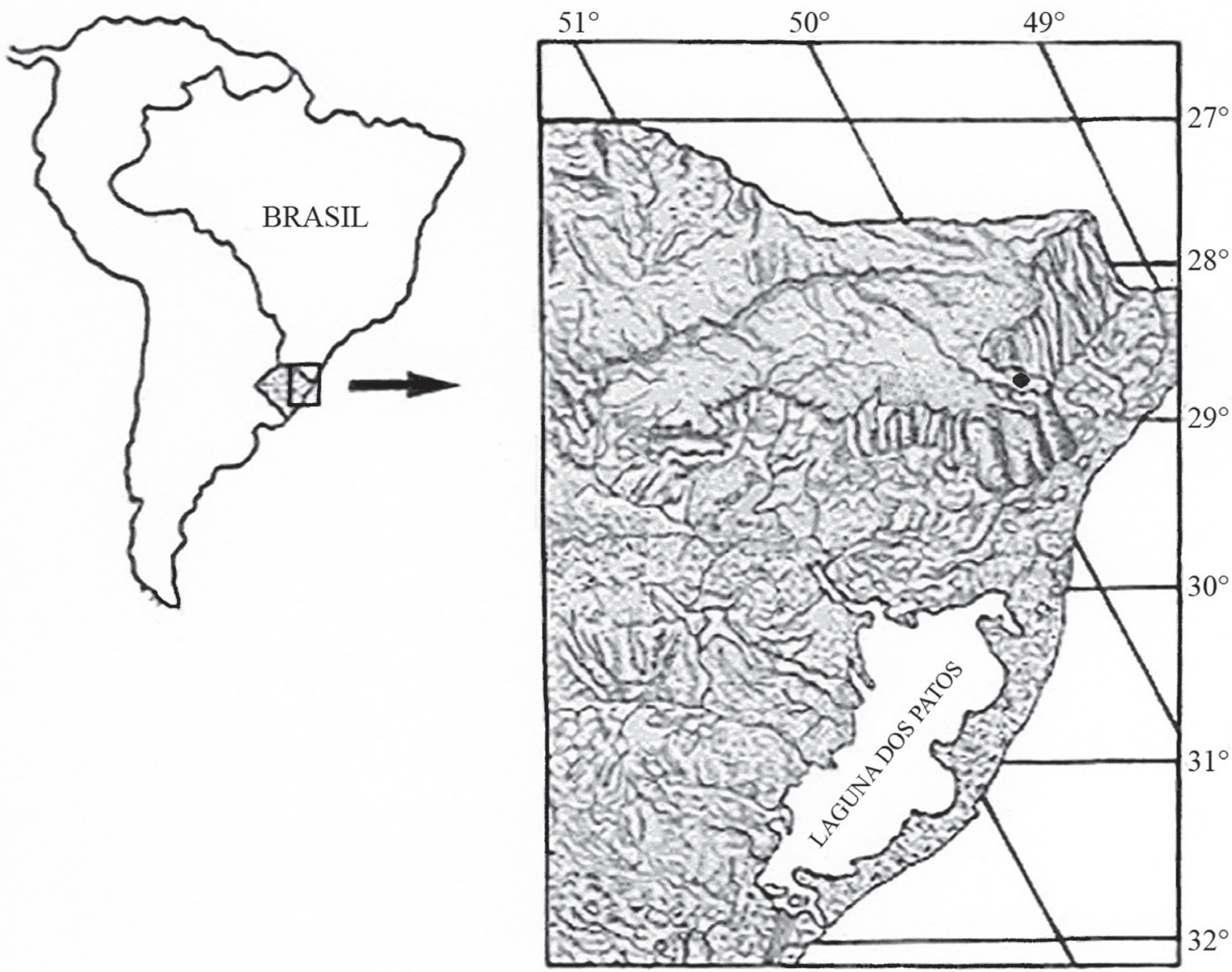

Figura 1. Estado do Rio Grande do Sul, Brasil, e localização do perfil sedimentar estudado. • Banhado Amarelo (29¹9’S e 5008’ W), São Francisco de Paula.

Figure 1. Rio Grande do Sul State, Brazil, and the location of the studied sedimentary profile. • Banhado Amarelo (29¹9'S and 5008' W), São Francisco de Paula. 
Para a identificação botânica utilizaramse a palinoteca de plantas atuais do Laboratório de Palinologia do Departamento de Botânica da Universidade Federal do Rio Grande do Sul e bibliografia especializada. Procurou-se sempre alcançar o nível taxonômico mais inferior possível. A palavra "Tipo" foi empregada quando os táxons não tiveram sua determinação assegurada devido à semelhança entre espécies, gêneros ou famílias, conforme o usual em palinologia de sedimentos (Berglund 1986). Foram acrescentados números após os nomes dos táxons nos casos em que os grãos, com morfologia distinta dentro de uma mesma categoria taxonômica, não puderam ser determinados em níveis mais inferiores, o que possibilita futura identificação. Números também foram atribuídos para separar material não determinado, caracterizado apenas pela morfologia, mas com nítidas diferenças morfológicas.

O pólen de cada táxon foi descrito de modo sucinto, usando-se as características morfológicas básicas para a identificação. A nomenclatura utilizada baseou-se no glossário de Punt et al. (2007). Medidas de eixos polar, equatorial ou o eixo único (nos casos de grãos apolares), permitiram determinar tamanho e categoria morfológica. Uma ocular de fio móvel foi usada nas medições, com conversão para micrômetros. Dados ecológicos do organismo de origem acompanham as descrições taxonômicas, fornecendo informações para análises paleoambientais.

A ordenação sistemática seguiu Bold et al. (1987) para gimnospermas e Cronquist (1981) para angiospermas.

\section{Resultados}

A análise taxonômica revelou um total de 46 táxons distintos, duas gimnospermas e 44 angiospermas, preservados ao longo do perfil sedimentar correspondente aos últimos 26.000 anos $\left({ }^{14} \mathrm{C}=26.080 \pm\right.$ 320 anos AP, Beta 245611).

\section{Gimnospermas}

Divisão PINOPHYTA

Classe PINOPSIDA

Ordem Pinales

Família Araucariaceae

1. Araucaria angustifolia (Bertol.) Kuntze

Figura 2
Globoso, aproximadamente esférico, radiossimétrico, isopolar. Robusto. Inaperturado, escabrado. Exina frágil, resultando em dobras irregulares. Presença de dois minúsculos descolamentos da exina, opostos, pouco perceptíveis. Diâmetro: $56-92 \mu \mathrm{m}$.

Dados ecológicos: típica do Sul e das regiões altomontanas do Sudeste do Brasil (Joly 1976, Reitz et al. 1983, Souza \& Lorenzi 2008). No do Rio Grande do Sul, ocorre em maior concentração no Planalto oriental. Espécie pioneira e heliófila, é a árvore mais importante e expressiva na fisionomia do Planalto, caracterizando a região (Rambo 1956). Irradia-se como elemento isolado sobre os campos limpos, formando agrupamentos, de início bastante esparsos, que vão se tornando cada vez mais densos, até constituir capões de pinhais. Preferencialmente em depressões dos campos, junto a cursos d'água, onde se iniciam os capões e matas de galeria, que se estendem por quase todos os campos (Reitz et al. 1983). Como pioneira, possibilita a expansão das florestas sobre os campos do Planalto (Backes \& Irgang 2002).

\section{Família Podocarpaceae}

\section{Podocarpus lambertii Klotzsch ex Endl.}

Figuras 3-4

Elipsoidal, oblato, bilateral, heteropolar. Bissacado, escabrado. Leptoma no pólo distal. Sacos grandes, formados por descolamento da exina, apresentando linhas finas e irregulares. Comprimento total (incluindo sacos): 61-77 $\mu \mathrm{m}$. Altura total (incluindo sacos): 34-60 $\mu \mathrm{m}$. Eixo equatorial maior (excluindo sacos): 32-60 $\mu \mathrm{m}$. Eixo equatorial menor (excluindo sacos): $29-53 \mu \mathrm{m}$. Eixo polar (excluindo sacos): cerca de $32 \mu \mathrm{m}$.

Dados ecológicos: ocorrência concentrada em florestas das regiões Sul e Sudeste do Brasil (Souza \& Lorenzi 2008). Distribuição limitada à zona da Araucária nos Estados do Sul do Brasil, com limite norte na Serra da Mantiqueira. (Reitz et al. 1983). Pioneira precursora em campos e capoeiras, com excelente regeneração natural em vegetação secundária (Backes \& Irgang 2002).

\section{Angiospermas}

\section{Divisão MAGNOLIOPHYTA \\ Classe MAGNOLIOPSIDA \\ Subclasse Magnoliidae}


Ordem Magnoliales

Família Winteraceae

\section{Drimys brasiliensis Miers}

Figuras 5-7

Tétrade tetraédrica. Grão globoso, levemente oblato, radiossimétrico, heteropolar. Monoulcerado, per-reticulado. Ulcus no pólo distal. Retículo grosseiro, irregularmente disposto, diminuindo em direção à abertura, até desaparecer junto ao ulcus. Columelas evidentes, sustentando o muro. Diâmetro da tétrade: cerca de $51 \mu \mathrm{m}$. Grão com eixo equatorial medindo cerca de $32 \mu \mathrm{m}$ e eixo polar com aproximadamente $25 \mu \mathrm{m}$.

Dados ecológicos: árvore pioneira de pequeno porte (Backes \& Irgang 2002), principalmente em áreas alagadas e em florestas de altitude do Sudeste e Sul do Brasil (Souza \& Lorenzi 2008). Acompanha a Mata com Araucária sobre o Planalto, na interface campo-floresta (Backes \& Irgang 2002). Esciófita ou de luz difusa, menos encontrada como heliófita. Levemente seletiva higrófita (Trinta \& Santos 1997).

\section{Subclasse Hamamelidae}

Ordem Urticales

\section{Urticales}

Figura 8

Subtriangular em vista polar, radiossimétrico, isopolar. Pequeno. Triporado, psilado. Estratificação obscura. Eixo equatorial: 21-32 $\mu \mathrm{m}$.

Dados ecológicos: ervas, arbustos ou árvores, em geral relacionados a ambiente de mata (Barroso 1978, Schultz 1990).

\section{Família Ulmaceae}

\section{Tipo Celtis L.}

Figuras 9-10

Circular em vista polar, radiossimétrico, isopolar. Triporado, psilado. Espessamento anelar ao redor dos poros. Columelas evidentes. Eixo equatorial: 25-31 $\mu \mathrm{m}$.

Dados ecológicos: gênero composto por árvores ou arbustos (Schultz 1990). Citada por Rambo (1994) para o Planalto do Rio Grande do Sul.

\section{Trema micrantha (L.) Blume}

Figuras 11-12

Oblato-esferoidal, bilateral. Elíptico nas vistas polar e equatorial, apolar. Pequeno. Biporado, ver- rucado. Espessamento ao redor dos poros, verrugas muito tênues. Columelas nem sempre evidentes. Eixo equatorial maior: 20-22 $\mu \mathrm{m}$. Diâmetro menor: 18-20 $\mu \mathrm{m}$.

Dados ecológicos: árvore considerada entre as pioneiras mais comuns no Sul do Brasil e também a mais amplamente distribuída. Importante na recomposição de áreas degradadas ou mesmo em reflorestamento inicial (Schultz 1990, Backes \& Irgang 2002). Ampla ocorrência, comum em florestas secundárias. (Souza \& Lorenzi 2008). Encontrada na orla das matas e nos capoeirões, onde é muito frequente (Reitz et al. 1983). Citada por Rambo (1994) para o Planalto do Rio Grande do Sul.

\section{Ordem Fagales \\ Família Betulaceae}

\section{Alnus Mill.}

Figura 13

Aproximadamente poligonal em vista polar, radiossimétrico, isopolar. Estefanoporado, psilado. Cinco poros apresentando espessamento anelar. Característicos espessamentos em forma de arco, conectando os poros. Columelas nem sempre evidentes. Eixo equatorial: $26-38 \mu \mathrm{m}$.

Dados ecológicos: em florestas nos Andes tropicais e subtropicais. Ausente no Brasil (Joly 1976, Souza \& Lorenzi 2008). Segundo Roth \& Lorscheitter (1993) indica ventos de oeste no Planalto do Rio Grande do Sul devido à capacidade de transporte a longas distâncias pela atmosfera.

\section{Subclasse Caryophyllidae \\ Ordem Caryophyllales \\ Família Amaranthaceae-Chenopodiaceae}

\section{Tipo Amaranthus L. - Chenopodiaceae}

\section{Figuras 14-17}

Esferoidal, radiossimétrico, apolar. Pequeno. Pantoporado, psilado. Poros numerosos e regularmente dispostos. Exina espessa, columelas evidentes. Diâmetro: cerca de $17 \mu \mathrm{m}$.

O pólen de Amaranthus e de Chenopodiaceae apresenta grande semelhança morfológica, tornando muito difícil a separação taxonômica.

Dados ecológicos: representantes de Amaranthus ocorrem como ervas ruderais (Joly 1976, Souza \& Lorenzi 2008). Chenopodiaceae compõem-se de ervas anuais ou perenes em campos (Barroso 1978, Schultz 1990). 
Família Amaranthaceae

\section{Tipo Iresine P. Browne 1}

Figuras 18-20

Esferoidal, radiossimétrico, apolar. Pequeno. Pantoporado, per-reticulado. Um poro em cada lúmen do retículo. Columelas evidentes, sustentando o muro. Diâmetro: cerca de $22 \mu \mathrm{m}$.

Dados ecológicos: gênero de ervas ou subarbustos anuais ou perenes, com distribuição nas regiões quentes e temperadas da América e África. Em campos secos e arenosos, clareiras ou borda de matas (Vasconcellos 1973, Schultz 1990). Citado por Rambo (1956) para o Planalto do Rio Grande do Sul.

\section{Tipo Iresine P. Browne 2}

Figuras 21-22

Esferoidal, radiossimétrico, apolar. Pantoporado, per-reticulado. Lumens robustos, dando ao grão um aspecto facetado. Um poro em cada lúmen do retículo. Columelas evidentes, sustentando o muro. Diâmetro: cerca de $37 \mu \mathrm{m}$.

Diferencia-se de Tipo Iresine 1 pelo tamanho do grão e pelo retículo com lumens proporcionalmente maiores.

Dados ecológicos: como em Tipo Iresine 1.

\section{Familia Caryophyllaceae}

\section{Caryophyllaceae}

Figuras 23-24

Esferoidal, radiossimétrico, apolar. Pantoporado, psilado. Poros regularmente dispostos, com espessamento anelar. Punctitegilado. Columelas evidentes. Diâmetro: $33-48 \mu \mathrm{m}$.

Dados ecológicos: ervas anuais ou perenes. Distribuição cosmopolita, concentrada em regiões temperadas (Joly 1976, Barroso 1978, Schultz 1990, Souza \& Lorenzi 2008). No Brasil, as espécies nativas podem ser encontradas em geral em ambientes abertos, principalmente em campos naturais e cerrados. Mais comuns na região Sul (Souza \& Lorenzi 2008).

\section{Subclasse Dilleniidae \\ Ordem Malvales \\ Família Malvaceae}

\section{Malvaceae}

Figuras 25-26

Circular em vista polar, radiossimétrico, isopolar. Robusto. Tetraporado, equinado. Poros com espessamento anelar. Espinhos grandes, com base larga, regularmente dispostos. Columelas evidentes. Eixo equatorial: 54-64 $\mu \mathrm{m}$.

Dados ecológicos: ervas, subarbustos ou arbustos, raramente árvores de pequeno porte (Joly 1976, Barroso 1978, Schultz 1990). Distribuição predominantemente pantropical, em distintos ambientes, como florestas estacionais, campos rupestres, bordas de manguezais, caatingas e cerrados (Souza \& Lorenzi 2008).

\section{Ordem Ericales \\ Família Ericaceae}

\section{Tipo Agarista D. Don ex G. Don Figuras 27-29}

Tétrade tetraédrica. Grão globoso, suboblato a oblato, radiossimétrico, isopolar. Tricolporado, psilado. Colporos com margo. Estratificação obscura. Diâmetro da tétrade: cerca de $45 \mu \mathrm{m}$. Eixo equatorial: cerca de $33 \mu \mathrm{m}$. Eixo polar: cerca de $24 \mu \mathrm{m}$.

Citado para o Rio Grande do Sul como Leucothoe D. Don.

Dados ecológicos: gênero de pequenos arbustos ou ervas, ocorrendo em campos de altitude do Sul e Sudeste do Brasil (Souza \& Lorenzi 2008), em diferentes condições edáficas no Planalto oriental do Rio Grande do Sul, como solos rochosos, campos, banhados, turfeiras ou capoeiras de topos de morro (Marques 1975).

\section{Ordem Primulales \\ Família Myrsinaceae}

\section{Myrsine L.}

Figura 30

Circular a levemente quadrangular em vista polar, radiossimétrico, isopolar. Tetracolporoidado, psilado. Columelas evidentes. Eixo equatorial: 28-38 $\mu \mathrm{m}$. Dados ecológicos: gênero de espécies arbóreas pioneiras, amplamente dispersadas pela fauna e com capacidade de desenvolvimento em qualquer tipo de solo (Backes \& Irgang 2002). Bem comum nas florestas do Sudeste brasileiro (Souza \& Lorenzi 2008). Citado por Rambo (1956) para o Planalto do Rio Grande do Sul.

\author{
Subclasse Rosidae \\ Ordem Fabales \\ Família Mimosaceae
}



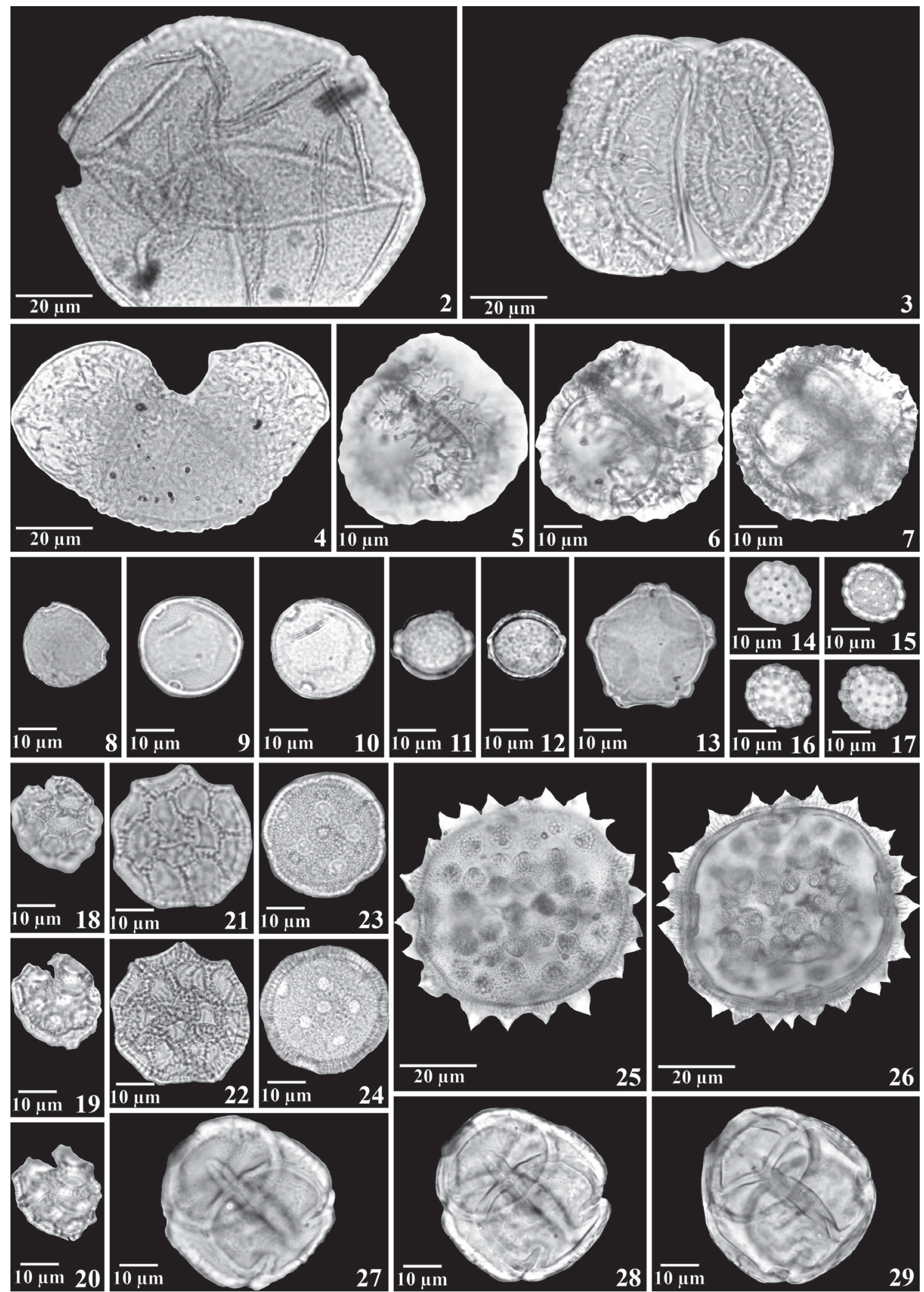

$27 \overline{10 \mu \mathrm{m}}$

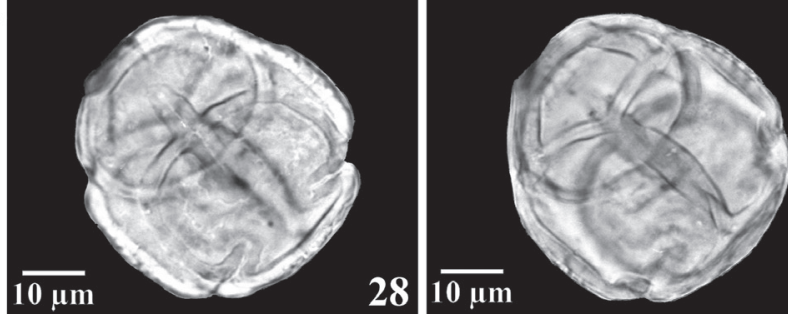

Figuras 2-4. Gimnospermas. 2. Araucaria angustifolia (dobras irregulares); 3-4. Podocarpus lambertii. 3. (PD), 4. (EQ). 5-29. Angiospermas. 5-7. Drimys brasiliensis: $1^{\circ}-3^{\circ} \mathrm{pl} ; 8$. Urticales $(\mathrm{P}) ; 9-10$. Tipo Celtis $(\mathrm{P}): 1^{\circ}-2^{\circ} \mathrm{pl} ; 11-12$. Trema micrantha: $1^{\circ}-2^{\circ} \mathrm{pl} ; 13$. Alnus $(\mathrm{P}) ; 14-$ 17. Tipo Amaranthus-Chenopodiaceae: $1^{\circ}-4^{\circ} \mathrm{pl} ; 18-20$. Tipo Iresine $1: 1^{\circ}-3^{\circ} \mathrm{pl} ; 21-22$. Tipo Iresine $2: 1^{\circ}-2^{\circ} \mathrm{pl} ; 23-24$. Caryophyllaceae: $1^{\circ}-2^{\circ} \mathrm{pl} ; 25-26$. Malvaceae $(\mathrm{P}): 1^{\circ}-2^{\circ} \mathrm{pl} ; 27-29$. Agarista: $1^{\circ}-3^{\circ} \mathrm{pl} .(\mathrm{pl}=$ planos; $\mathrm{P}=$ vista polar; $\mathrm{PD}=$ pólo distal; $\mathrm{EQ}=$ vista equatorial). Figures 2-4. Gymnospermae. 2. Araucaria angustifolia (irregular folds); 3-4. Podocarpus lambertii. 3. (PD), 4. (EQ). 5-29. Angiospermae. 5-7. Drimys brasiliensis: $1^{\circ}-3^{\circ} \mathrm{pl} ; 8$. Urticales (P); 9-10. Celtis type (P): $1^{\circ}-2^{\circ} \mathrm{pl} ; 11-12$. Trema micrantha: $1^{\circ}-2^{\circ} \mathrm{pl} ; 13$. Alnus $(\mathrm{P}) ; 14-$ 17. Amaranthus-Chenopodiaceae type: $1^{\circ}-4^{\circ} \mathrm{pl} ; 18-20$. Iresine type $1: 1^{\circ}-3^{\circ} \mathrm{pl} ; 21-22$. Iresine type $2: 1^{\circ}-2^{\circ} \mathrm{pl} ; 23-24$. Caryophyllaceae: $1^{\circ}-2^{\circ} \mathrm{pl} ; 25-26$. Malvaceae $(\mathrm{P}): 1^{\circ}-2^{\circ} \mathrm{pl} ; 27-29$. Agarista: $1^{\circ}-3^{\circ} \mathrm{pl}$. $(\mathrm{pl}=$ planes; $\mathrm{P}=$ polar view; $\mathrm{PD}=$ distal pole; $\mathrm{EQ}=\mathrm{equatorial}$ view). 
15. Mimosa scabrella Benth.

\section{Figura 31}

Tétrade tetraédrica, pequena e hialina. Grão oblato, radiossimétrico, levemente heteropolar. Pequeno. Aproximadamente circular em vista polar. Poros não evidentes, psilado. Estratificação obscura. Diâmetro da tétrade: 11-15 $\mu \mathrm{m}$. Grão com eixo equatorial medindo cerca de $8 \mu \mathrm{m}$ e eixo polar com aproximadamente $6 \mu \mathrm{m}$.

Dados ecológicos: árvore pioneira mais importante da mata com Araucária, encontrada no limite entre a mata e o campo. Os nódulos radiculares e a queda das folhas permitem incorporação de nitrogênio e fósforo ao solo (Backes \& Irgang 2002). Característica do Planalto sul-brasileiro (Schultz 1990). Heliófita, em especial nas associações secundárias, podendo formar densos agrupamentos (Burkart 1979). Vastamente dispersa pelos capoeirões do Planalto oriental do Rio Grande do Sul, onde está circunscrita à mata com Araucária, situada em maiores altitudes, entre 700 e 1.200 metros (Reitz et al. 1983).

\section{Mimosa ser. Lepidotae Benth.}

\section{Figura 32}

Tétrade tetragonal, elíptica em vista frontal. Grão suboblato, radiossimétrico, heteropolar. Pólo distal alargado, pólo proximal nitidamente afilado. Porado, verrucado. Poros equatoriais, salientes na zona de contato entre os grãos. Verrugas tênues. Columelas evidentes. Diâmetro da tétrade: 31-35 $\mu \mathrm{m}$. Grão com eixo equatorial entre 17-22 $\mu \mathrm{m}$ e eixo polar entre 13-17 $\mu \mathrm{m}$.

Dados ecológicos: subarbusto até árvore, em locais úmidos a pantanosos (Burkart 1979, Lins \& Baptista 1990).

\section{Família Fabaceae}

\section{Tipo Vicia L.}

Figuras 33-34

Prolato, radiossimétrico, isopolar. Robusto. Elíptico em vista equatorial. Tricolporado, per-reticulado. Retículo tênue e fino. Endoabertura conspícua, circular. Columelas evidentes. Eixo equatorial: $36-43 \mu \mathrm{m}$. Eixo polar: 58-65 $\mu \mathrm{m}$.

Dados ecológicos: gênero com espécies nativas do Brasil normalmente de porte baixo, trepadeiras, com gavinhas. Comuns em campos do Estado, entremeadas a espécies herbáceas ou arbustivas, formando touceiras ou prostradas sobre o solo, ou em margem de caminhos (Bastos 1996, Schultz 1990). Rambo (1956) cita o gênero para o Planalto do Rio Grande do Sul.

\author{
Ordem Haloragales \\ Família Haloragaceae
}

\section{Myriophyllum L.}

Figuras 35-37

Aproximadamente quadrangular em vista polar, radiossimétrico, isopolar. Tetraporado, psilado a levemente verrucado. Poros salientes com espessamento anelar. Columelas evidentes. Eixo equatorial: 30-34 $\mu \mathrm{m}$.

Dados ecológicos: gênero de ervas aquáticas ou palustres, ocorrendo principalmente na região Sul do Brasil. Rápido crescimento, com ramos submersos e aéreos (Fevereiro 1975, Souza \& Lorenzi 2008).

$$
\begin{aligned}
& \text { Ordem Myrtales } \\
& \text { Família Lythraceae }
\end{aligned}
$$

\section{Cuphea carunculata Koehne}

Figura 38

Triangular em vista polar, radiossimétrico, isopolar. Tricolporado, psilado. Zonas interangulares aproximadamente retilíneas. Aberturas nos ângulos, nitidamente projetadas. Columelas nem sempre evidentes. Eixo equatorial: 22-27 $\mu \mathrm{m}$.

Dados ecológicos: Cuphea distribui-se na América do Sul e Central, em regiões quentes e temperadas. Compõe-se de ervas ou arbustos de campos úmidos ou secos, podendo também ocorrer em borda de mata, mata aberta, em clareiras ou mesmo banhados (Lourteig 1969).

\section{Família Myrtaceae}

\section{Myrtaceae \\ Figura 39}

Triangular em vista polar, radiossimétrico, isopolar. Tricolporado, psilado. Colporos unidos na região do apocólpio, formando uma figura triangular. Zonas interangulares retilíneas a levemente convexas. Columelas nem sempre evidentes. Eixo equatorial: $19-28 \mu \mathrm{m}$.

Dados ecológicos: árvores ou arbustos, raramente subarbustos, distribuição predominantemente pantropical e subtropical. (Schultz 1990, Souza \& Lorenzi 2008). Encontram-se entre as famílias mais comuns da maioria das formações vegetais, com destaque para a Floresta Atlântica e para a Floresta de Restinga (Souza \& Lorenzi 2008). Contém o maior número de espécies da flora arbórea no Rio Grande do Sul. Des- 
taca-se também pela grande densidade de ocorrência em diferentes formações florestais (Sobral 2003).

Família Melastomataceae

\section{Melastomataceae}

Figura 40

Prolato, radiossimétrico, isopolar. Tricolporado, psilado. Pseudocolpos intercalados aos colporos. Estratificação obscura. Eixo equatorial: cerca de $19 \mu \mathrm{m}$. Eixo polar: 33-40 $\mu \mathrm{m}$.

Dados ecológicos: ervas, arbustos ou árvores, menos frequentemente epífitas ou lianas (Souza \& Lorenzi 2008). Tropicais ou subtropicais, maioria na América do Sul (Barroso 1984, Joly 1976, Schultz 1990). Encontra-se entre as principais famílias da flora brasileira (Souza \& Lorenzi 2008), com várias espécies no Planalto do Rio Grande do Sul (Rambo 1956).

Ordem Santalales

Família Loranthaceae

\section{Phrygilanthus Eichler}

\section{Figura 41}

Triangular em vista polar, com zonas interangulares côncavas e ângulos truncados. Radiossimétrico, isopolar. Tricolporado, colporos unidos na região do apocólpio. Exina frouxa na zona equatorial interangular, formando uma camada hialina de projeções densamente dispostas. Eixo equatorial: 26-30 $\mu \mathrm{m}$.

Dados ecológicos: gênero de plantas hemiparasitas, sobre árvores (Schultz 1990). Citado por Rambo (1956) para o Planalto do Rio Grande do Sul.

\section{Ordem Celastrales}

Família Aquifoliaceae

\section{Ilex $\mathrm{L}$.}

\section{Figuras 42-44}

Prolato-esferoidal a prolato, radiossimétrico, isopolar. Elíptico em vista equatorial. Tricolporado, clavado. Clavas pequenas, densamente dispostas. Estratificação obscura. Eixo equatorial: 26-35 $\mu \mathrm{m}$.

Eixo polar: $34-45 \mu \mathrm{m}$.

Dados ecológicos: constituído por arbustos ou árvores. Distribuição cosmopolita, ocorrendo principalmente nos estados do Sul e Sudeste do Brasil (Souza \& Lorenzi 2008). No Sul é encontrado nas matas do Planalto, da encosta atlântica e da restinga litorânea (Edwin \& Reitz 1967).
Ordem Euphorbiales

Família Euphorbiaceae

24. Alchornea triplinervia (Spreng.) Müll. Arg.

Figuras 45-46

Subprolato, radiossimétrico, isopolar. Circular em vista polar. Tricolporado, psilado. Opérculos alongados nas aberturas. Columelas evidentes. Eixo equatorial: 25-35 $\mu \mathrm{m}$. Eixo polar: cerca de $31 \mu \mathrm{m}$. Dados ecológicos: arbustos ou árvores (Smith et al. 1988). Espécie polimórfica de ampla distribuição, ocorrendo em quase todas as formações naturais (Souza \& Lorenzi 2008). Muito abundante nas matas do Sul do Brasil (Schultz 1990, Backes \& Irgang 2002). Mais frequente em áreas abertas, como clareiras ou matas alteradas. Regenera-se abundantemente nas capoeiras (Backes \& Irgang 2002).

\section{Tipo Croton L.}

Figuras 47-49

Esférico, radiossimétrico, apolar, frequentemente com dobras irregulares. Robusto. Inaperturado, verrucado. Verrugas dispostas em padrão Croton. Diâmetro: 47-65 $\mu \mathrm{m}$.

Dados ecológicos: gênero de árvores, arbustos ou ervas, em regiões tropicais (Smith et al. 1988). Em campos, brejos, pântanos (Marchant et al. 2002). Comum em quase todos os ecossistemas brasileiros (Souza \& Lorenzi 2008). Rambo (1956) cita o gênero para o Planalto do Rio Grande do Sul.

\section{Ordem Polygalales \\ Família Polygalaceae}

\section{Polygala L.}

Figuras 50-51

Prolato, radiossimétrico, isopolar. Estefanocolporado, psilado. Colporos longos e estreitos, com endoaberturas unidas formando uma faixa contínua na região equatorial. Columelas pouco evidentes. Eixo equatorial: 21-23 $\mu \mathrm{m}$. Eixo polar: $31-35 \mu \mathrm{m}$. Dados ecológicos: gênero composto por ervas ou arbustos, anuais, bianuais ou perenes. (Lüdtke \& Miotto 2004). Ampla distribuição, especialmente em áreas neotropicais, exceto Austrália e Nova Zelândia (Marques \& Gomes 2002). Em solos secos ou úmidos, campos, banhados, turfeiras, bordas de mata, dunas e margem de estrada (Lüdtke \& Miotto 2004).

Ordem Sapindales

Família Sapindaceae 


\section{Sapindaceae}

Figuras 52-53

Triangular em vista polar, radiossimétrico, isopolar. Tricolporado, per-reticulado. Colporos unidos na região do apocolpio, formando uma figura triangular. Retículo muito fino. Columelas evidentes. Eixo equatorial: cerca de $42 \mu \mathrm{m}$.

Dados ecológicos: arbustos, árvores ou lianas, ocasionalmente ervas. Distribuição cosmopolita, ocorrendo principalmente nos trópicos e subtrópicos, raramente nas regiões temperadas (Barroso 1984, Schultz 1990, Souza \& Lorenzi 2008). A família é citada por Rambo (1956) para o Planalto do Rio Grande do Sul.

Família Anacardiaceae

\section{Anacardiaceae}

Figuras 54-55

Prolato, radiossimétrico, isopolar. Elíptico em vista equatorial. Tricolporado, per-reticulado-estriado. Colporos longos, encurvados. Columelas evidentes, sustentando o muro. Eixo equatorial: cerca de 22 $\mu \mathrm{m}$. Eixo polar: cerca de $36 \mu \mathrm{m}$.

Dados ecológicos: arbustos ou árvores, raramente lianas ou ervas. Distribuição predominantemente tropical e subtropical, ocorrendo também nas regiões temperadas (Joly 1976, Barroso 1984, Souza \& Lorenzi 2008), em diversos ambientes, como interior ou borda de matas poucos densas, capões, margem de riachos, encostas de morros e campos alterados (Fleig 1987). Família citada por Rambo (1956) para a mata com Araucária.

\section{Ordem Apiales \\ Família Apiaceae}

\section{Eryngium L.}

Figuras 56-58

Subprolato a perprolato, radiossimétrico, isopolar. Elíptico a elíptico-comprimido em vista equatorial. Tricolporado, psilado. Colporos longos com endoaberturas retangulares. Columelas evidentes. Eixo equatorial: 19-37 $\mu \mathrm{m}$. Eixo polar: 36-46 $\mu \mathrm{m}$.

Dados ecológicos: gênero de ervas geralmente campestres (Schultz 1990), podendo ocorrer em capoeiras, locais encharcados, pântanos, lagoas e turfeiras (Irgang 1974). Frequentes nos campos e brejos do Brasil meridional (Joly 1976). Possuem grande expressão na Região Sul do Brasil, principalmente em áreas alagáveis (Souza \& Lorenzi 2008). No Rio Grande do Sul encontra-se principalmente na região do Planalto (Aparados da Serra e Campos de Cima da Serra) segundo Irgang 1974.

\section{Ordem Lamiales \\ Família Lamiaceae}

\section{Lamiaceae}

Figuras 59-61

Aproximadamente circular em vista polar, radiossimétrico, isopolar. Em geral robusto, tamanho variável. Estefanocolpado, per-reticulado. Seis colpos. Columelas evidentes, sustentando o muro. Eixo equatorial: $35-56 \mu \mathrm{m}$.

Provavelmente as distintas diferenças em tamanho estejam relacionadas a diferentes táxons dentro da família.

Dados ecológicos: ervas anuais ou perenes, subarbustos ou arbustos, raramente árvores de pequeno porte. Distribuição cosmopolita, em regiões montanhosas subtropicais (Joly 1976, Barroso 1986, Schultz 1990, Souza \& Lorenzi 2008).

\section{Ordem Plantaginales \\ Família Plantaginaceae}

\section{Plantago L.}

Figuras 62-63

Esférico, radiossimétrico, apolar. Pantoporado, verrucado. Poros tênues e distanciados. Verrugas delicadas. Columelas evidentes. Diâmetro: 26-35 $\mu \mathrm{m}$. Dados ecológicos: gênero de plantas herbáceas campestres ou ruderais, ocorrendo em terrenos arenosos de restinga, campos secos até pantanosos, banhados e turfeiras (Rahn 1966). Cosmopolita, preferindo zonas temperadas e frias (Schultz 1990). É citado por Rambo (1956) para o Planalto do Rio Grande do Sul.

\section{Ordem Scrophulariales

$$
\text { Família Scrophulariaceae }
$$

\section{Tipo Scrophulariaceae}

Figuras 64-66

Subprolato a prolato, radiossimétrico, isopolar. Muito pequeno e hialino. Elipsoidal em vista equatorial. Tricolporado, per-reticulado. Retículo muito fino e tênue. Estratificação obscura. Eixo equatorial: 8-11 $\mu \mathrm{m}$. Eixo polar: cerca de $14 \mu \mathrm{m}$.

Dados ecológicos: família de ervas, subarbustos ou arbustos, menos frequentemente árvores. Distribuição cosmopolita (Barroso 1986, Schultz 1990, Souza \& Lorenzi 2008). Várias espécies campestres ou ru- 

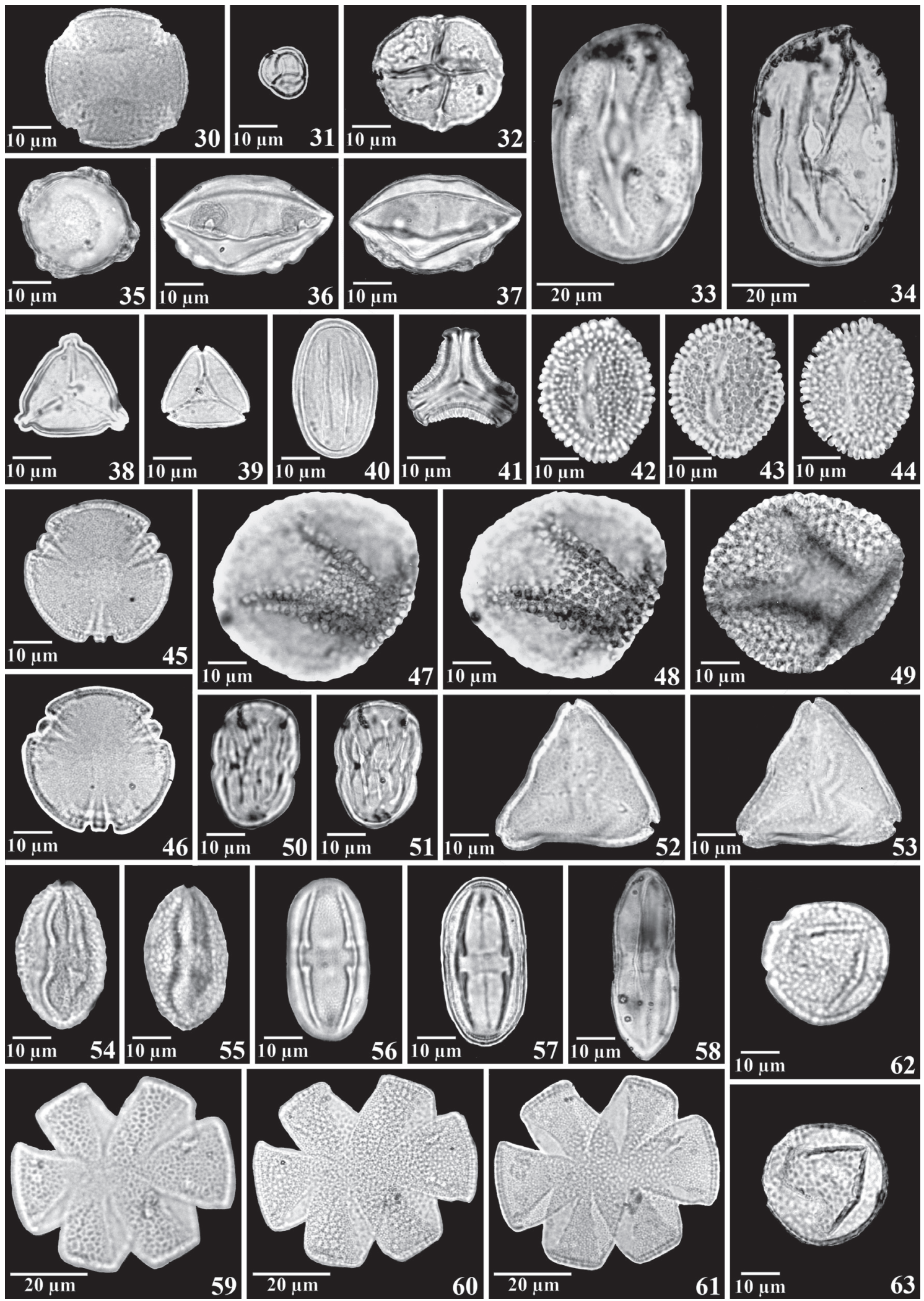

Figuras 30-63. Angiospermas. 30. Myrsine (P); 31. Mimosa scabrella; 32. Mimosa ser. Lepidotae; 33-34. Tipo Vicia (EQ): $1^{\circ}-2^{\circ} \mathrm{pl} ; 35-37$. Myriophyllum. 35 (P), 36-37 (com dobras, OB): $1^{\circ}-2^{\circ}$ pl; 38. Cuphea carunculata (P); 39. Myrtaceae (P); 40. Melastomataceae (EQ); 41. Phrygilanthus $(\mathrm{P}) ; 42-44$. Ilex: $1^{\circ}-3^{\circ} \mathrm{pl} ; 45-46$. Alchornea triplinervia $(\mathrm{P}): 1^{\circ}-2^{\circ} \mathrm{pl} ; 47-49$. Tipo Croton: $1^{\circ}-3^{\circ} \mathrm{pl} ; 50-51$. Polygala $(\mathrm{EQ})$ : $1^{\circ}-2^{\circ} \mathrm{pl} ; 52-53$. Sapindaceae (P): $1^{\circ}-2^{\circ} \mathrm{pl}$; 54-55. Anacardiaceae (EQ): $1^{\circ}-2^{\circ} \mathrm{pl}$; 56-58. Eryngium (EQ). 56-57: $1^{\circ}-2^{\circ} \mathrm{pl} ; 59-61$. Lamiaceae (P): $1^{\circ}-3^{\circ} \mathrm{pl} ; 62-63$. Plantago: $1^{\circ}-2^{\circ} \mathrm{pl}$. $(\mathrm{pl}=$ planos; $\mathrm{P}=$ vista polar; $\mathrm{EQ}=$ vista equatorial, $\mathrm{OB}=$ oblíquo $)$.

Figures 30-63. Angiospermae. 30. Myrsine (P); 31. Mimosa scabrella; 32. Mimosa ser. Lepidotae; 33-34. Vicia type (EQ): $1^{\circ}-2^{\circ} \mathrm{pl} ; 35-37$. Myriophyllum. 35 (P), 36-37 (with folds, OB): $1^{\circ}-2^{\circ}$ pl; 38. Cuphea carunculata (P); 39. Myrtaceae (P); 40. Melastomataceae (EQ); 41. Phrygilanthus $(\mathrm{P}) ; 42-44$. Ilex: $1^{\circ}-3^{\circ} \mathrm{pl} ; 45-46$. Alchornea triplinervia $(\mathrm{P}): 1^{\circ}-2^{\circ} \mathrm{pl} ; 47-49$. Croton type: $1^{\circ}-3^{\circ} \mathrm{pl} ; 50-51$. Polygala $(\mathrm{EQ})$ : $1^{\circ}-2^{\circ} \mathrm{pl} ; 52-53$. Sapindaceae (P): $1^{\circ}-2^{\circ} \mathrm{pl} ; 54-55$. Anacardiaceae (EQ): $1^{\circ}-2^{\circ} \mathrm{pl} ; 56-58$. Eryngium (EQ). 56-57: $1^{\circ}-2^{\circ} \mathrm{pl} ; 59-61$. Lamiaceae $(\mathrm{P}): 1^{\circ}-3^{\circ} \mathrm{pl} ; 62-63$. Plantago: $1^{\circ}-2^{\circ} \mathrm{pl}$. ( $\mathrm{pl}=$ planes; $\mathrm{P}=$ polar view; $\mathrm{EQ}=$ equatorial view, $\mathrm{OB}=$ oblique $)$. 
derais no Brasil (Ichaso \& Barroso 1970).

Família Bignoniaceae

\section{Bignoniaceae}

Figuras 67-71

Subprolato, radiossimétrico, isopolar. Em geral robusto. Aproximadamente circular em vista polar, elíptico em vista equatorial. Tricolpado, per-reticulado. Columelas evidentes, sustentando o muro. Eixo equatorial: 32-70 $\mu \mathrm{m}$. Eixo polar: cerca de $42 \mu \mathrm{m}$.

Provavelmente as distintas diferenças em tamanho estejam relacionadas a diferentes táxons dentro da família.

Dados ecológicos: plantas lenhosas, arbustivas ou arbóreas, também lianas (Joly 1976, Souza \& Lorenzi 2008). Distribuição pantropical, predominantemente neotrópica, poucas distribuídas nas zonas temperadas (Barroso 1986, Schultz 1990, Souza \& Lorenzi 2008). Rambo (1956) cita várias espécies para o Planalto do Rio Grande do Sul.

Ordem Dipsacales

Família Valerianaceae

\section{Valeriana $\mathrm{L}$.}

Figuras 72-75

Subprolato, radiossimétrico, isopolar. Circular em vista polar, circular a elíptico em vista equatorial. Tricolpado, microequinado. Colpos longos. Espinhos muito finos, distanciados, regularmente distribuídos. Columelas evidentes. Eixo equatorial: 30-36 $\mu \mathrm{m}$. Eixo polar: cerca de $36 \mu \mathrm{m}$.

Dados ecológicos: gênero de ervas ou subarbustos, raramente trepadeiras. Ocorre em campos rupestres, interior e margem de florestas, margem de matas de galeria e banhados (Sobral 1999). Maioria das espécies encontradas em campos de altitude no Brasil (Souza \& Lorenzi 2008). Ampla distribuição no Rio Grande do Sul (Sobral 1999).

Ordem Asterales

Família Asteraceae

\section{Tipo Baccharis L. 1}

Figuras 76-78

Subprolato, radiossimétrico, isopolar. Circular em vista polar, circular a elíptico em vista equatorial. Tricolporado, equinado. Espinhos conspícuos, regularmente distribuídos. Columelas evidentes. Eixo equatorial: 28-31 $\mu \mathrm{m}$. Eixo polar: 29-32 $\mu \mathrm{m}$.
Dados ecológicos: gênero de ervas ou arbustos, frequentes nos campos do Brasil (Joly 1976, Souza \& Lorenzi 2008). Segundo Rambo (1956), muitos se destacam nos campos do Planalto do Rio Grande do Sul.

36. Tipo Baccharis L. 2

Figuras 79-80

Oblato esferoidal, radiossimétrico, isopolar. Circular em vista equatorial. Tricolporado, equinado. Espinhos pequenos, regularmente distribuídos. Columelas evidentes. Eixo equatorial: cerca de $26 \mu \mathrm{m}$. Eixo polar: cerca de $24 \mu \mathrm{m}$.

Diferencia-se do Tipo Baccharis 1 pelos espinhos nitidamente menores.

Dados ecológicos: como no Tipo Baccharis 1.

\section{Tipo Mutisia L. f. 1}

Figuras 81-82

Subprolato a prolato, radiossimétrico, isopolar. Robusto. Elíptico-fusiforme em vista equatorial, com pólos projetados. Tricolporado, psilado. Colporos longos. Endoabertura lalongada, unindo-se às demais para formar uma faixa contínua ao redor do equador. Exina biestratificada com columelas evidentes. Estrato inferior mais espesso na zona equatorial, tornando-se mais fino que o estrato superior nos pólos. Eixo equatorial: 38-42 $\mu \mathrm{m}$. Eixo polar: 49-60 $\mu \mathrm{m}$.

Dados ecológicos: gênero de ervas, arbustos, lianas e árvores. Maioria das espécies com formas de vida relacionadas principalmente a ambientes campestres (Mondim 1996).

\section{Tipo Mutisia L. f. 2}

Figuras 83-84

Subprolato, radiossimétrico, isopolar. Aproximadamente elíptico-fusiforme em vista equatorial, com pólos levemente afilados. Tricolporado, rugulado. Colporos longos, endoabertura circular, com espessamento marginal. Exina biestratificada com columelas evidentes. Estratos com espessura uniforme. Eixo equatorial: cerca de $33 \mu \mathrm{m}$. Eixo polar: cerca de $39 \mu \mathrm{m}$.

Diferencia-se do Tipo Mutisia 1 pelo tamanho menor do grão, pela ornamentação rugulada e pelas columelas dispostas em estratos com espessura uniforme.

Dados ecológicos: como no Tipo Mutisia 1.

\section{Tipo Mutisia L. f. 3}

Figuras 85-86

Prolato, radiossimétrico, isopolar. Oval em vista equatorial. Tricolporado, rugulado. Exina 
biestratificada com columelas evidentes. Estratos com espessura uniforme. Eixo equatorial: 32-38 $\mu \mathrm{m}$. Eixo polar: $60-67 \mu \mathrm{m}$.

Diferencia-se do Tipo Mutisia 1 e do Tipo Mutisia 2 principalmente pelo formato oval e alongado do grão.

Dados ecológicos: como no Tipo Mutisia 1.

40. Tipo Vernonia Schreb.

Figuras 87-90

Subtriangular em vista polar, radiossimétrico, isopolar. Tricolporado, per-reticulado equinado, lofado. Muro muito alto portando espinhos robustos, regularmente distribuídos, podendo mascarar as aberturas. Columelas evidentes, sustentando o muro. Eixo equatorial: $37-42 \mu \mathrm{m}$.

Dados ecológicos: gênero de ervas, subarbustos, arbustos e árvores. Ocorre em distintos ambientes como campos, banhados, capoeiras, borda e interior de matas e margem de rios, também como ruderais (Matzenbacher \& Mafioleti 1994). Espécies do gênero são frequentes nos campos do Brasil (Souza \& Lorenzi 2008), muitas ocorrendo no Planalto do Rio Grande do Sul (Rambo 1956).

\section{Classe LILIOPSIDA \\ Subclasse Commelinidae \\ Ordem Cyperales \\ Família Cyperaceae}

\section{Cyperaceae}

Figuras 91-93

Prolato-esferoidal a subprolato, radiossimétrico, heteropolar. Pólo distal em geral alargado, afilando em direção ao pólo proximal. Inaperturado, monoulcerado ou sulcado com um número variável de sulcos na região equatorial. Escabrado, ornamentação mais grosseira nas aberturas. Columelas nem sempre evidentes. Eixo equatorial: 35-37 $\mu \mathrm{m}$. Eixo polar: 40$43 \mu \mathrm{m}$.

Dados ecológicos: família de ervas de pequeno porte, geralmente rizomatosas, raramente lianas ou plantas arborescentes. Distribuição cosmopolita. No Brasil, principalmente em áreas abertas e alagáveis, podendo ser também relativamente comum nas bordas de florestas (Joly 1976, Souza \& Lorenzi 2008). Rambo (1956) cita vários gêneros e espécies para o Planalto do Rio Grande do Sul.

Família Poaceae

\section{Poaceae}

Figuras 94-95

Esférico, radiossimétrico, heteropolar, em geral com dobras irregulares. Circular nas vistas polar e equatorial. Monoporado, psilado. Poro no pólo distal com espessamento anelar. Columelas evidentes. Eixo equatorial: 45-60 $\mu \mathrm{m}$. Eixo polar: cerca de $52 \mu \mathrm{m}$. Dados ecológicos: família de ervas geralmente rizomatosas, às vezes lignificadas (bambus), perenes ou anuais. Distribuição cosmopolita, principal componente das formações campestres em todo o mundo (Joly 1976, Schultz 1990, Souza \& Lorenzi 2008). No Rio Grande do Sul existem em distintos ambientes de campo. Poucas espécies de mata no Rio Grande do Sul (Boldrini et al. 2005).

\section{Subclasse Liliidae \\ Ordem Liliales \\ Família Liliaceae}

\section{Tipo Liliaceae 1}

Figuras 96-99

Elíptico em vista polar, bilateral, heteropolar. Monossulcado, per-reticulado. Sulco longo no pólo distal. Retículo fino, de variado tamanho de lúmen. Columelas evidentes. Eixo equatorial maior: 32-49 $\mu \mathrm{m}$. Eixo equatorial menor: 22-27 $\mu \mathrm{m}$.

Dados ecológicos: família composta por ervas perenes, geralmente bulbosas (Joly 1976, Schultz 1990, Souza \& Lorenzi 2008). Em quase todo o mundo, desde a zona quente até as temperadas. Poucos gêneros no Brasil (Joly 1976).

\section{Tipo Liliaceae 2}

Figuras 100-102

Elíptico em vista polar, bilateral, heteropolar. Monossulcado, per-reticulado. Sulco longo no pólo distal. Retículo grosseiro. Columelas evidentes. Eixo equatorial maior: cerca de $53 \mu \mathrm{m}$. Eixo equatorial menor: cerca de $32 \mu \mathrm{m}$.

Diferencia-se do Tipo Liliaceae 1 pelo tamanho maior do grão e diâmetro mais avantajado dos lumens do retículo.

Dados ecológicos: como no Tipo Liliaceae 1.

Outros grãos de pólen

45. Tricolporado 1

Figuras 103-106

Prolato-esferoidal, radiossimétrico, isopolar. Subtriangular em vista polar, aproximadamente 

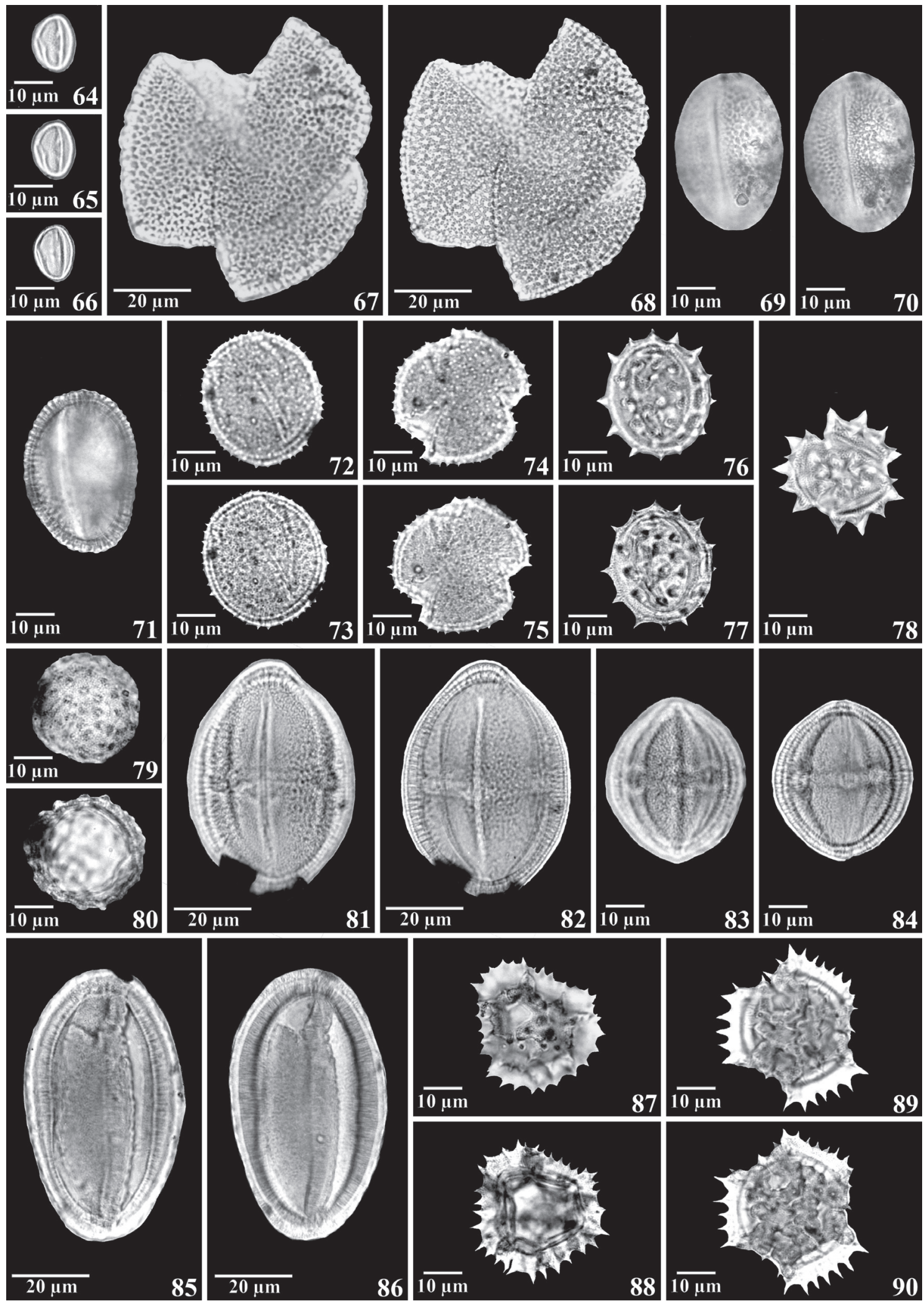

89
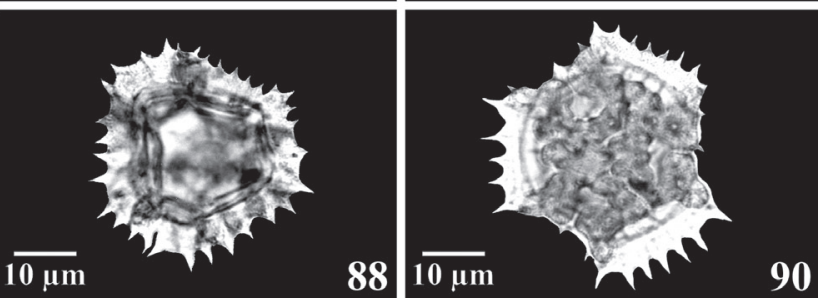

Figuras 64-90. Angiospermas. 64-66. Tipo Scrophulariaceae (EQ): $1^{\circ}-3^{\circ} \mathrm{pl} ; 67-71$. Bignoniaceae. 67-68 (P): $1^{\circ}-2^{\circ} \mathrm{pl}, 69-71$ (outra espécie, EQ): $1^{\circ}-3^{\circ} \mathrm{pl} ; 72-75$. Valeriana. $72-73$ (EQ): $1^{\circ}-2^{\circ} \mathrm{pl}, 74-75$ (P): $1^{\circ}-2^{\circ} \mathrm{pl} ; 76-78$. Tipo Baccharis $1.76-77$ (EQ): $1^{\circ}-2^{\circ} \mathrm{pl}, 78(\mathrm{P}) ; 79-80$. Tipo Baccharis 2 (P): $1^{\circ}-2^{\circ} \mathrm{pl}$; 81-82. Tipo Mutisia 1 (EQ): $1^{\circ}-2^{\circ}$ pl; 83-84. Tipo Mutisia 2 (EQ): $1^{\circ}-2^{\circ}$ pl; 85-86. Tipo Mutisia 3 (EQ): $1^{\circ}-2^{\circ} \mathrm{pl} ; 87-90$. Tipo Vernonia. $87-88(\mathrm{P}): 1^{\circ}-2^{\circ} \mathrm{pl}, 89-90(\mathrm{P}): 1^{\circ}-2^{\circ} \mathrm{pl} .(\mathrm{pl}=$ planos; $\mathrm{P}=$ vista polar; $\mathrm{EQ}=$ vista equatorial).

Figures 64-90. Angiospermae. 64-66. Scrophulariaceae type (EQ): $1^{\circ}-3^{\circ} \mathrm{pl} ; 67-71$. Bignoniaceae. $67-68(\mathrm{P}): 1^{\circ}-2^{\circ} \mathrm{pl}, 69-71$ (other species, EQ): $1^{\circ}-3^{\circ} \mathrm{pl} ; 72-75$. Valeriana. $72-73(\mathrm{EQ}): 1^{\circ}-2^{\circ} \mathrm{pl}, 74-75(\mathrm{P}): 1^{\circ}-2^{\circ} \mathrm{pl}$; 76-78. Baccharis type 1. $76-77(\mathrm{EQ}): 1^{\circ}-2^{\circ} \mathrm{pl}, 78(\mathrm{P}) ; 79-$ 80. Baccharis type $2(\mathrm{P}): 1^{\circ}-2^{\circ} \mathrm{pl} ; 81-82$. Mutisia type 1 (EQ): $1^{\circ}-2^{\circ} \mathrm{pl} ; 83-84$. Mutisia type 2 (EQ): $1^{\circ}-2^{\circ}$ pl; 85-86. Mutisia type 3 (EQ): $1^{\circ}-2^{\circ} \mathrm{pl} ; 87-90$. Vernonia.type 87-88 (P): $1^{\circ}-2^{\circ} \mathrm{pl}, 89-90(\mathrm{P}): 1^{\circ}-2^{\circ} \mathrm{pl}$. ( $\mathrm{pl}=$ planes; $\mathrm{P}=$ polar view; $\mathrm{EQ}=$ equatorial view). 
circular em vista equatorial. Tricolporado, perreticulado. Columelas longas, sustentando o muro. Eixo equatorial: 20-27 $\mu \mathrm{m}$. Eixo polar: cerca de 21 $\mu \mathrm{m}$.

\section{Tricolporoidado 1}

Figuras 107-108

Perprolato, radiossimétrico, isopolar. Elíptico em vista equatorial. Tricolporoidado, psilado. Columelas evidentes. Eixo equatorial: cerca de $17 \mu \mathrm{m}$. Eixo polar: cerca de $35 \mu \mathrm{m}$.

Os resultados evidenciaram uma grande riqueza no material polínico, incluindo duas gimnospermas e
44 angiospermas, num total de 46 táxons preservados no perfil sedimentar da turfeira do Banhado Amarelo no intervalo de tempo correspondente aos últimos 26.000 anos. Os distintos táxons provêm de ambientes muito variados, evidenciando seu grande potencial como material de referência em reconstituições paleoambientais dos últimos milênios em sedimentos de turfeiras do Planalto do Sul do Brasil.

\section{Agradecimentos}

As autoras agradecem as bolsas de pesquisa concedidas e os auxílios financeiros do CNPq e da CAPES, fundamentais para o desenvolvimento desta pesquisa.
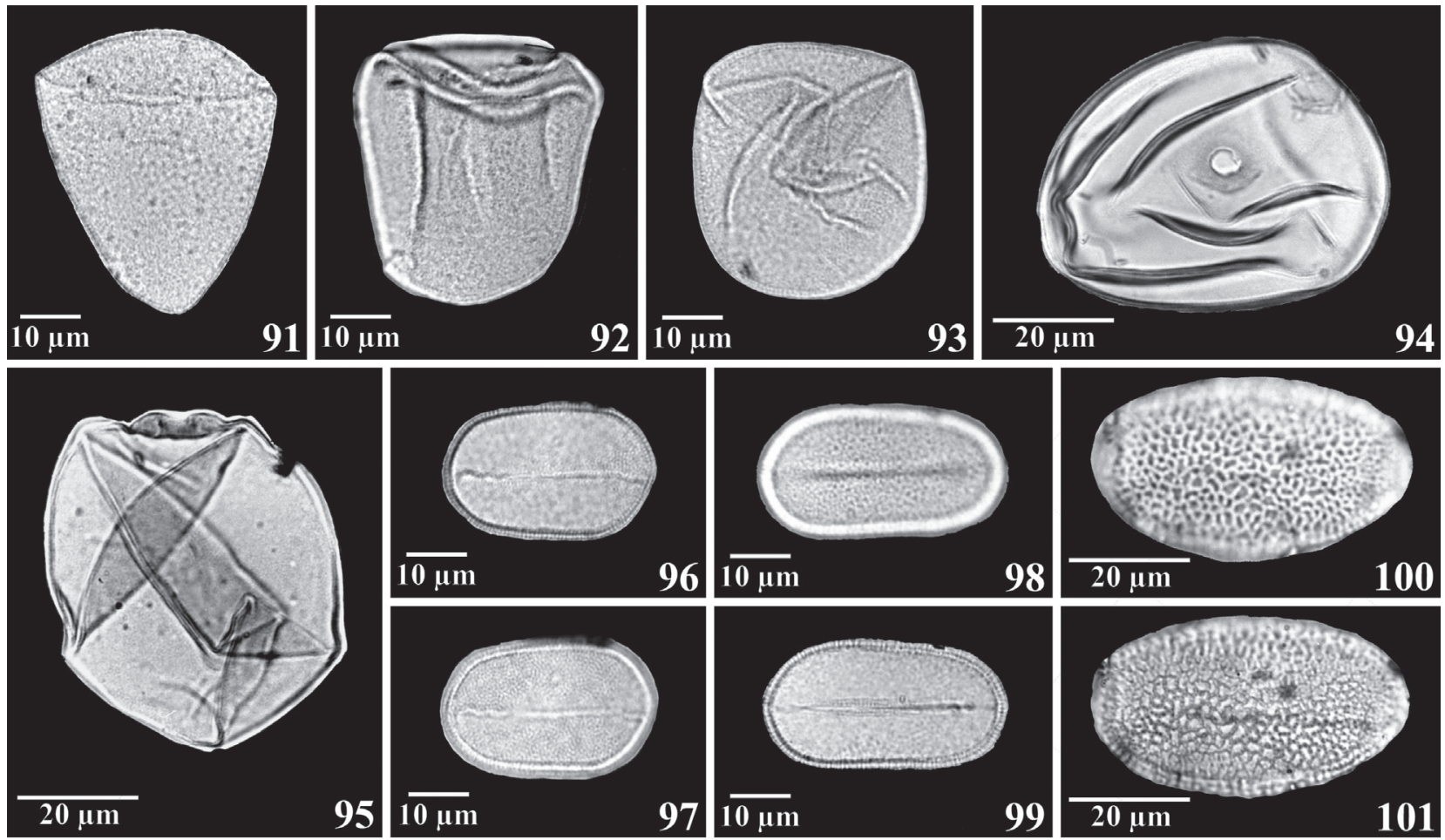

96
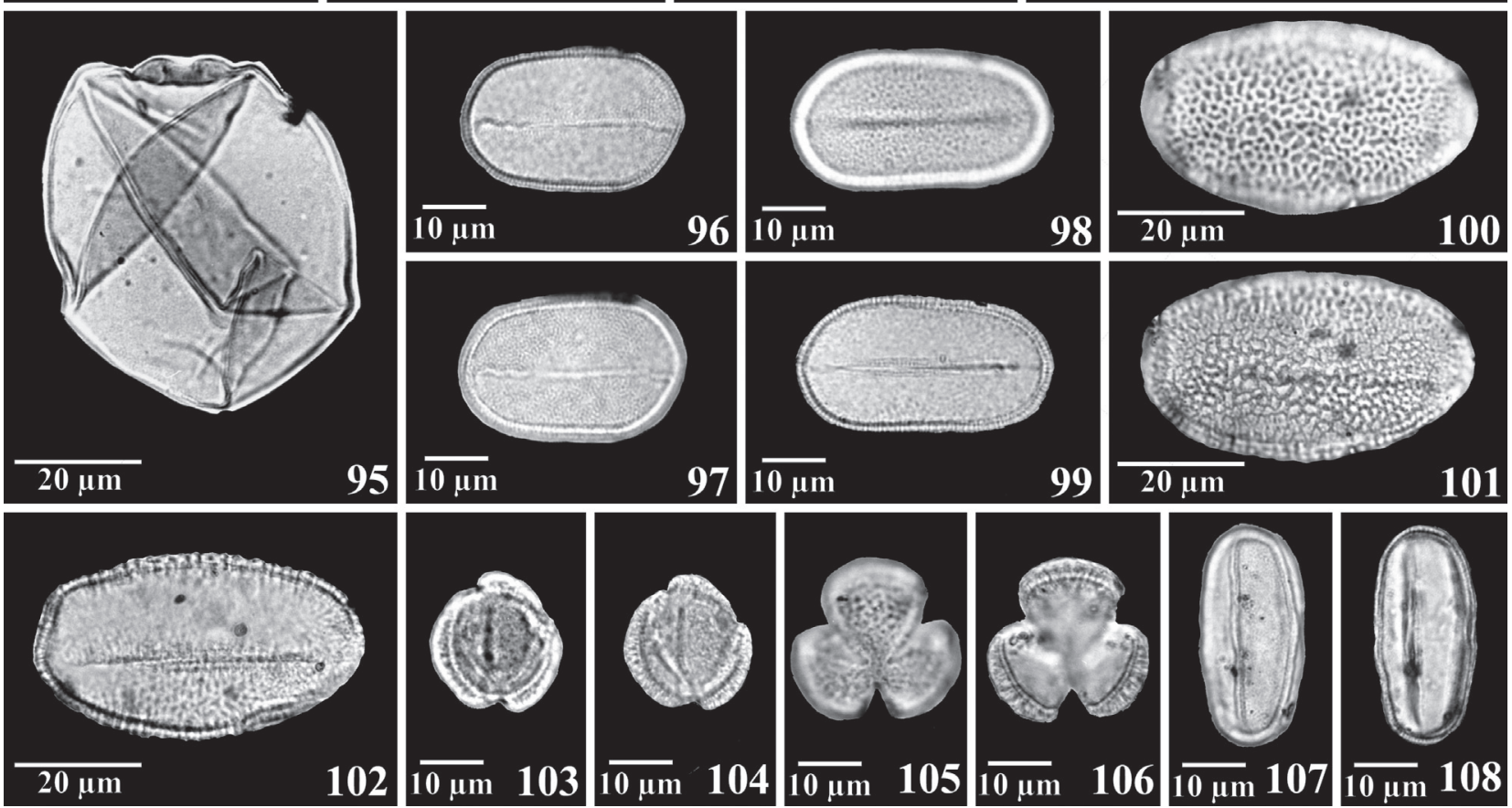

Figuras 91-108. Angiospermas. 91-93. Cyperaceae, com dobras. 91-92 (EQ), 93 (OB); 94-95. Poaceae, com dobras. 94 (PD), 95 (EQ); 96-99. Tipo Liliaceae 1. 96-97 (PD): $1^{\circ}-2^{\circ} \mathrm{pl}, 98-99$ (PP, sulco visto por transparência): $1^{\circ}-2^{\circ} \mathrm{pl}$; $100-102$. Tipo Liliaceae 2 (PP, sulco visto por transparência): $1^{\circ}-3^{\circ} \mathrm{pl}$; 103-106. Tricolporado 1. 103-104 (EQ): $1^{\circ}-2^{\circ} \mathrm{pl}, 105-106$ (P): $1^{\circ}-2^{\circ}$ pl; 107-108. Tricolporoidado 1 (EQ): $1^{\circ}-2^{\circ}$ pl. $(\mathrm{pl}=$ planos; $\mathrm{P}=$ vista polar; $\mathrm{PP}=$ pólo proximal; $\mathrm{PD}=$ pólo distal; $\mathrm{EQ}=$ vista equatorial; $\mathrm{OB}=$ oblíquo).

Figures 91-108. Angiospermae. 91-93. Cyperaceae, with folds. 91-92 (EQ), 93 (OB); 94-95. Poaceae, with folds. 94 (PD), 95 (EQ); $96-$ 99. Liliaceae type 1. 96-97 (PD): $1^{\circ}-2^{\circ} \mathrm{pl}, 98-99$ (PP, sulcus seen due to transparency): $1^{\circ}-2^{\circ} \mathrm{pl} ; 100-102$. Liliaceae type 2 (PP, sulcus seen due to transparency): $1^{\circ}-3^{\circ} \mathrm{pl} ; 103-106$. Tricolporate $1.103-104$ (EQ): $1^{\circ}-2^{\circ} \mathrm{pl}, 105-106$ (P): $1^{\circ}-2^{\circ}$ pl; 107-108. Tricolporoidate 1 (EQ): $1^{\circ}-2^{\circ}$ pl. $(\mathrm{pl}=$ planes; $\mathrm{P}=$ polar view; $\mathrm{PP}=$ proximal pole; $\mathrm{PD}=$ distal pole; $\mathrm{EQ}=$ equatorial view; $\mathrm{OB}=$ oblique $)$. 


\section{Literatura citada}

Backes, P. \& Irgang, B.E. 2002. Árvores do Sul. Guia de Identificação e Interesse Ecológico. Instituto Souza Cruz, Porto Alegre.

Barroso, G.M. 1978. Sistemática de angiospermas do Brasil. v. 1. Editora Universidade de São Paulo, São Paulo.

Barroso, G.M. 1984. Sistemática de angiospermas do Brasil. v. 2. Universidade Federal de Viçosa, Imprensa Universitária, Viçosa.

Barroso, G.M. 1986. Sistemática de angiospermas do Brasil. v. 3. Universidade Federal de Viçosa, Imprensa Universitária, Viçosa.

Bastos, N.R. 1996. O gênero Vicia L. (Leguminosae - Faboideae) no Brasil. Dissertação de Mestrado, Universidade Federal do Rio Grande do Sul, Porto Alegre.

Berglund, B.E. 1986. Handbook of Holocene Palaeoecology and Palaeohydrology. John Wiley \& Sons, New York.

Bold, H.C., Alexopoulos, C.J. \& Delevoryas, T. 1987. Morphology of plants and fungi. 5 ed. Harper \& Row Publishers, New York.

Boldrini, I.I., Longhi-Wagner, H.M. \& Boechat, S.C. 2005. Morfologia e taxonomia de gramíneas sul-rio-grandenses. Editora da Universidade Federal do Rio Grande do Sul, Porto Alegre.

Burkart, A. 1979. Leguminosas, Mimosóideas. In: Flora Ilustrada Catarinense (R. Reitz, ed.). Herbário Barbosa Rodrigues, Itajaí.

Cronquist, A. 1981. An integrated system of classification of flowering plants. Columbia University Press, New York.

Edwin, G. \& Reitz, R. 1967. Aqüifoliáceas. In: Flora Ilustrada Catarinense (R. Reitz, ed.). Herbário Barbosa Rodrigues, Itajaí.

Faegri, K. \& Iversen, J. 1989. Textbook of pollen analysis. 4 ed. John Wiley \& Sons, New York.

Fevereiro, P.C.A. 1975. Haloragáceas. In: Flora Ilustrada Catarinense (R. Reitz, ed.). Herbário Barbosa Rodrigues, Itajaí.

Fleig, M. 1987. Anacardiaceae. Boletim do Instituto de Biociências 42: 1-72.

Ichaso, C.L.F. \& Barroso, G.M. 1970. Escrofulariáceas. In: Flora Ilustrada Catarinense (R. Reitz, ed.). Herbário Barbosa Rodrigues, Itajaí.

Irgang, B.E. 1974. Umbelliferae. Boletim do Instituto de Biociências 32: 1-86.

Joly, A.B. 1976. Botânica: introdução à taxonomia vegetal. 13 ed. Editora Nacional, São Paulo.
Leonhardt, A. 2007. Mudanças vegetacionais e climáticas no Planalto leste do Rio Grande do Sul, Brasil, durante os últimos 25000 anos. Dissertação de Mestrado, Universidade Federal do Rio Grande do Sul, Porto Alegre.

Leonhardt, A. \& Lorscheitter, M.L. 2007. Palinomorfos do perfil sedimentar de uma turfeira em São Francisco de Paula, Planalto Leste do Rio Grande do Sul, Sul do Brasil. Revista Brasileira de Botânica 30: 47-59.

Leonhardt, A. \& Lorscheitter, M.L. 2008. Pólen de gimnospermas e angiospermas do perfil sedimentar de uma turfeira em São Francisco de Paula, Planalto Leste do Rio Grande do Sul, Sul do Brasil. Revista Brasileira de Botânica 31: 645-658.

Lins, D.M.T. \& Baptista, L.R.M. 1990. Considerações taxonômicas sobre algumas espécies de Mimosa da série Lepidotae do Rio Grande do Sul. In: M.F. Silva (coord.). Anais do XXXV Congresso Nacional de Botânica, 1984. Sociedade Botânica do Brasil, Manaus.

Lourteig, A. 1969. Litráceas. In: Flora Ilustrada Catarinense (R. Reitz, ed.). Herbário Barbosa Rodrigues, Itajaí.

Lüdtke, R. \& Miotto, S.T.S. 2004. O gênero Polygala L. (Polygalaceae) no Rio Grande do Sul, Brasil. Revista Brasileira de Biociências 2: 49-102.

Marchant, R., Almeida, L., Behling, H., Berrio, J.C., Bush, M., Cleef, A., Duivenvoorden, J., Kappelle, M., Oliveira, P., Oliveira Filho, A.T., Lozano-Garcia, S., Hooghiemstra, H., Ledru, M.P., Ludlow-Wiechers, B., Markgraf, V., Mancini, V., Paez, M., Prieto, A., Rangel, O. \& Salgado-Labouriau, M.L. 2002. Distribution and ecology of parent taxa of pollen lodged within the Latin American Pollen Database. Review of Palaeobotany and Palynology 121: 1-75.

Marques, M.C.M. 1975. Ericáceas. In: Flora Ilustrada Catarinense (R. Reitz, ed.). Herbário Barbosa Rodrigues, Itajaí.

Marques, M.C.M. \& Gomes, K. 2002. Flora fanerogâmica do Estado de São Paulo: Polygalaceae. v. 2. Editora Rima, São Paulo.

Matzenbacher, N.I. \& Mafioleti, S.I. 1994. Estudo taxonômico do gênero Vernonia Schreb. (Asteraceae) no Rio Grande do Sul, Brasil. Comunicações do Museu de Ciências e Tecnologia PUCRS, Série Botânica 1: 1-133.

Mondim, C.A. 1996. A tribo Mutisieae Cass. (Astereaceae) sensu Cabrera, no Rio Grande do Sul 
e suas relações biogeográficas. Dissertação de Mestrado, Universidade Federal do Rio Grande do Sul, Porto Alegre.

Punt, W., Blackmore, S., Nilsson, S. \& Thomas, A.L.E. 2007. Glossary of pollen and spore terminology. Review of Paleobotany and Palynology 143: 1-81.

Rahn, K. 1966. Plantagiáceas. In: Flora Ilustrada Catarinense (R. Reitz, ed.). Herbário Barbosa Rodrigues, Itajaí.

Rambo, B. 1956. A flora fanerogâmica dos Aparados riograndenses. Sellowia 7: 235-298.

Rambo, B. 1994. A fisionomia do Rio Grande do Sul - ensaio de monografia natural. 3 ed. Editora Universidade do Vale do Rio dos Sinos, São Leopoldo.

Reitz, R., Klein, R.M. \& Reis, A. 1983. Projeto madeira do Rio Grande do Sul. Sellowia 34/35: $1-525$.

Roth, L. 1990. Palinologia de uma turfeira do Parque Nacional de Aparados da Serra, Planalto Leste do Rio Grande do Sul, Brasil. Dissertação de Mestrado, Universidade Federal do Rio Grande do Sul, Porto Alegre.

Roth, L. \& Lorscheitter, M.L. 1993. Palynology of a bog in Parque Nacional de Aparados da Serra, East Plateau of Rio Grande do Sul, Brazil. Quaternary of South America and Antarctic Peninsula 8: 39-69.

Roth, L. \& Lorscheitter, M.L. 2008. Palinomorfos de um perfil sedimentar em uma turfeira do Parque Nacional dos Aparados da Serra, leste do Planalto do Rio Grande do Sul, Brasil. Iheringia, Série Botânica 63: 69-100.

Scherer, C. 2008. Sucessão vegetal e reconstituição de paleoambientes no interior de matas com Araucária, Planalto leste do Rio Grande do Sul,
Brasil. Tese de Doutorado, Universidade Federal do Rio Grande do Sul, Porto Alegre.

Scherer, C. \& Lorscheitter, M.L. 2008. Palinomorfos de fungos e criptógamas em sedimentos quaternários de duas matas com Araucária, Planalto leste do Rio Grande do Sul, Brasil. Acta Botanica Brasilica 22: 131-144.

Scherer, C. \& Lorscheitter, M.L. 2009. Pólen de gimnospermas e angiospermas em sedimentos quaternários de duas matas com Araucária, planalto leste do Rio Grande do Sul, Brasil. Acta Botanica Brasilica 23: 681-696.

Schultz, A.R. 1990. Introdução à botânica sistemática. v. 2.5 ed. Sagra, Editora da Universidade Federal do Rio Grande do Sul, Porto Alegre.

Smith, L.B. Downs, R.J. \& Klein, R.M. 1988. Euforbiáceas. In: Flora Ilustrada Catarinense (R. Reitz, ed.). Herbário Barbosa Rodrigues, Itajaí.

Sobral, M. 1999. Valerianaceae. Boletim do Instituto de Biociências 58: 1-61.

Sobral, M. 2003. A família Myrtaceae no Rio Grande do Sul. Editora Universidade do Vale do Rio dos Sinos, São Leopoldo.

Souza, V.C. \& Lorenzi, H. 2008. Botânica sistemática: guia ilustrado para identificação de Angiospermas da flora brasileira, baseado em APG II. 2 ed. Instituto Plantarum, Nova Odessa.

Spalding, B.B.C. \& Lorscheitter, M.L. 2009. Palinologia de sedimentos da turfeira do Banhado Amarelo, São Francisco de Paula, Rio Grande do Sul, Brasil. Fungos e criptógamas. Hoehnea 36: 219-232.

Trinta, E.F. \& Santos, E. 1997. Winteráceas. In: Flora Ilustrada Catarinense (R. Reitz, ed.). Herbário Barbosa Rodrigues, Itajaí.

Vasconcellos, J.M.O. 1973. Estudo dos gêneros de Amaranthaceae do Rio Grande do Sul. Iheringia, série Botânica 18: 90-97. 